\title{
EL PRIMOGÉNITO DE ALBURQUERQUE, DE R. LÓPEZ SOLER: LA LUCHA POR LA CORONA DE CASTILLA
}

\author{
ENRIQUe RUBIo CREMADES \\ Universidad de Alicante
}

\section{RESUMEN}

La novela El primogénito de Alburquerque, de R. López Soler, puede considerarse como una de las obras más importantes de la narrativa histórica del Romanticismo. En el presente estudio se analizan las fuentes históricas relacionadas con Pedro i el Cruel y su hermanastro Enrique de Trastámara, desde la Crónica de López de Ayala hasta los romances referidos a dichos personajes. Hechos históricos que se entrecruzan con las aventuras y desventuras de Martín Gil, el primogénito de Alburquerque, un héroe literario cuyos hechos se engarzan con las rivalidades entre estos dos personajes históricos.

Palabras clave: Romanticismo, López Soler, Novela, Pedro i el Cruel, Enrique de Trastámara.

\section{Abstract}

The novel El primogénito de Alburquerque, by R. López Soler, can be considered one of the most important works of the historical narrative of Romanticism. In the present study we analyze the historical sources related to Pedro I the Cruel and his stepbrother Enrique de Trastámara, from the Crónica of Lopez de Ayala to the romances that refer to these characters. Historical events that intersect with the adventures and misadventures of Martín Gil, the firstborn of Alburquerque, a literary hero whose events are intertwined with the rivalries between these two historical characters.

KeY words: Romanticism, López Soler, Novel, Pedro i el Cruel, Enrique de Trastámara.

La literatura romántica se nutre constantemente de situaciones dramáticas acaecidas en la Edad Media. Cuando el escritor se despoja del material noticioso proveniente del extranjero y busca en su propio entramado histórico las fuentes primordiales para su ficción, tal como constata el propio López Soler en sus artículos 
publicados en El Europeo ${ }^{1}$, El Vapor $^{2}$ y, fundamentalmente, en el prólogo que precede a su novela histórica Los bandos de Castilla ${ }^{3}$, tanto las novelas y dramas como las leyendas y el cuento, fundamentalmente, se sustentan desde el punto de vista de la ficción literaria de hechos históricos provenientes de nuestros propios orígenes y enmarcados en la Edad Media. Contexto histórico pródigo en rivalidades nobiliarias, asesinatos, infidelidades conyugales, adulterios, desavenencias matrimoniales, persecuciones implacables... La novela histórica española desde sus inicios engarza con no poca profusión todas estas situaciones, tal como se constata en los relatos, entre otros, de

\begin{abstract}
${ }^{1}$ En El Europeo R. López Soler publicó artículos referidos a las polémicas literarias existentes en la época entre clásicos y románticos. Sus reflexiones, harto interesantes, manifiestan una postura ecléctica, conciliadora, próxima a Larra, aunque en la práctica, como escritor de novelas se mostrara más proclive a la escuela romántica que a la neoclásica. Sus artículos publicados en El Europeo, «Análisis de la cuestión agitada entre románticos y clasicistas» y «Conclusión del análisis de la cuestión agitada entre románticos y clasicistas (continuación)» dan probada muestra de sus conocimientos literarios sobre la literatura española y europea en general. Conocedor también de la literatura medieval y áurea, de ahí sus continuas comparaciones o cotejos entre los escritores de estas épocas con los neoclásicos. Su talante conciliador queda perfectamente reflejado en el texto en el que afirma que los «clasicistas violentan la situación del alma, los románticos la desvían, pero muy suavemente, de su temple natural; el lenguaje de aquellos es más magnífico, el de estos más penetrante; los primeros tienen por base a las pasiones y hablan al mundo físico; los segundos tienen por base el sentimiento y hablan al mundo moral» (I, 7 [1823], p. 208). En la segunda y última entrega concluye con elogios a ambas escuelas, pues afirma taxativamente que es necesario consultar las dos escuelas, «las dos religiones, de donde sacan los poetas de ambos partidos sus inmensos materiales, y nos convenceremos de que también parece la observancia de las reglas en los que adoran a Júpiter de los griegos, como el abandonarse a los raptos de la fantasía en los que adoran al Jehová de los cristianos» (I, 8 [1823], p. 258).
\end{abstract}

${ }^{2}$ En la publicación periódica El Vapor (1833-1836) López Soler mantuvo como director inicial de dicha publicación una línea romántica, en clara consonancia con los nuevos postulados europeos. El 22 de marzo de 1833, fecha de inicio de la publicación, figura como director del periódico y también por estas fechas muestra una prolífica labor creativa. Su estrecha amistad con el excelente editor Bergnes de las Casas, en cuya imprenta inició su andadura El Vapor, posibilitó la publicación de varias novelas cuyos contenidos remitían al lector a un universo romántico, histórico, plagado de aventuras, de bandidos famosos, de rivalidades nobiliarias, de raptos, como Enrique de Lorena (1832), Jaime el Barbudo (1832), KarOsman o Memorias de la casa de Silva (1832), novelas publicadas por Bergnes de las Casas, al igual que la titulada Las señoritas de hogaño y las doncellas de antaño bien distinta al mundo de ficción de las anteriores novelas, pues es una obra imitada del célebre Scribe -La demoiselle et la dame, ou avant et après-cuya producción literaria hacía furor en la España romántica, tal como constata Larra en sus artículos de crítica teatral.

${ }^{3}$ En el prólogo que figura al frente de su novela Los bandos de Castilla manifiesta con no poca claridad cuál es su ideario estético, su credo literario y su intención al novelar la corte de Juan II. Como es bien sabido su intención no es otra que difundir la obra de W. Scott y, fundamentalmente, «manifestar que la historia de España ofrece pasajes tan bellos y propios para despertar la atención de los lectores como los de Escocia y de Inglaterra. A fin de conseguir uno y otro intento hemos traducido al novelista inglés en algunos pasajes e imitándole en otros muchos, procurando dar a su narración y a sus diálogos aquella vehemencia de que comúnmente, por acomodarse al carácter grave y flemático de los pueblos para quienes escribe» (Los bandos de Castilla o El Caballero del Cisne. Novela original española, Valencia, Imprenta de Cabrerizo, 1830, I, p. III). Los hechos de la historia de España son los motivos esenciales de las novelas de López Soler, fundamentalmente, Los bandos de Castilla y El primogénito de Alburquerque, pues se centran en dos episodios históricos convulsos, apasionantes, plagados de intrigas, de pasiones. Rasgos que se adecuan perfectamente a sus sentimientos románticos: «Libre, impetuosa, salvaje por decirlo así, tan admirable en el osado vuelo de sus inspiraciones, como sorprendente en sus sublimes desvaríos, puédese afirmar que la literatura romántica es la intérprete de aquellas pasiones vagas e indefinibles [...]» (Ibidem, I, p. VII). 
Húmara, Trueba y Cosío, López Soler, Larra, Espronceda, Vayo, Cortada, Escosura, Ochoa y Gil y Carrasco. No olvidemos tampoco la relación de leyendas y romances referidos a dicha época, como los debidos al duque de Rivas, cuyo complejo mundo narrativo remite al lector a motivos desarrollados en El Primogénito de Alburquerque, como los titulados Una antigualla en Sevilla (Pedro I autor de un asesinato), El Alcázar de Sevilla (muerte de Fadrique) y El fratricidio (Tragedia de Montiel). Asunto que también subyace en las leyendas de fondo histórico de Zorrilla, como la titulada Justicias del Rey don Pedro o en los romances de Roca de Togores, fundamentalmente el titulado Enrique de Trastámara en Bañeres, 1867. No menos interesante sería la leyenda de José Joaquín de Mora titulada El Bastardo en la que contrapone con claridad el libertinaje y la crueldad de Alfonso XI y Pedro i con la honradez, pundonor y decoro de Enrique de Trastámara. Leyenda que resume en buena medida lo relatado por el propio López Soler en El primogénito de Alburquerque, pues alude de forma sucinta a los caracteres propios de los personajes principales de su novela y a los episodios históricos más relevantes o sobresalientes habidos entre Pedro i y Enrique de Trastámara. Tanto en Rivas como en José Joaquín de Mora se percibe una gran inquina contra Pedro I, atrayéndoles más la violencia y horrores cometidos por el monarca que sus cualidades y obras que le granjearon el sobrenombre de El Justiciero. No faltan tampoco leyendas en las que Enrique de Trastámara aparece como un ser antónimo de la virtud, del honor, por ser el autor de la muerte de su hermanastro Pedro I, como en la leyenda de Zorrilla Los borceguíes de don Enrique II en la que el rey de Granada, amigo y aliado de Pedro I, obsequia a don Enrique unos borceguíes envenenados que le provocan la muerte. Poesía narrativa en pro de Pedro i el Cruel que contrasta con los ejemplos anteriormente citados, como la obra de Romero Larrañaga Comprar el trono de un pueblo con la sangre de un hermano ${ }^{4}$.

Las desavenencias entre Pedro i y Enrique de Trastámara, así como la plasmación de episodios históricos medievales en general, se constatan también en la dramaturgia romántica española ${ }^{5}$, como en la célebre obra de Zorrilla El zapatero

\footnotetext{
${ }^{4}$ G. Romero Larrañaga, Cuentos históricos, leyendas antiguas y tradiciones populares de España, Madrid, I. Boix, 1841. Presencia también de leyendas en las que se narran los amores de don Pedro I al final de su vida y su relación amorosa con la joven Luz, como en la leyenda de María Pilar Sinués, «El ángel de la muerte. Leyenda histórica del siglo IV», en Mis vigilias, Zaragoza, Imprenta, Cristóbal Juste y Olona, 1854.
}

\footnotetext{
${ }^{5}$ A lo largo del Romanticismo el público en general asiste al teatro consciente del bello y truculento espectáculo que le ofrece el mundo medieval, pues contempla con no poco interés una serie de episodios históricos plagados de rivalidades entre nobles y monarcas, infidelidades amorosas, adulterios, desavenencias conyugales, enfrentamientos familiares, rivalidades por la sucesión en el trono... García Gutiérrez - El bastardo, Doña Urraca de Castilla - sería un claro ejemplo de la materialización de parte de estos aspectos. Hartzenbusch, prolífico autor de dramas, engarza también el hecho histórico con sucesos acaecidos en la novela de R. López Soler El primogénito de Alburquerque: las rivalidades amorosas o el tratamiento del amor en determinados personajes, como en el drama Alfonso el Casto -tratamiento de la relación amorosa entre el conde de Saldaña y doña Jimena, hermana del rey-, El infante don Fernando de
} 
y el rey, aunque el primer escritor en llevar al teatro las vivencias trágicas entre don Pedro y su hermano fuera Espronceda con su tragedia Blanca de Borbón, escrita entre los años 1830 y 1831. Obra definida por R. Marrast como «parábola del mal rey» ${ }^{6}$ y en la que Espronceda identifica a Pedro I con el absolutismo de Fernando VII. Tragedia cuyo mundo de ficción apenas difiere del universo novelesco de El Primogénito de Alburquerque, a pesar de que don Fadrique, el Gran Maestre de Santiago, hermanastro de Pedro I, es sustituido por su gemelo, Enrique de Trastámara. Los actos primero y segundo guardan estrechas semejanzas con el relato de López Soler y salvo esta circunstancia apuntada, las concomitancias son evidentes, pues el comportamiento de María de Padilla, su hermano Diego García y el sector de la nobleza protagonista de la conspiración ofrecen un gran parecido. En ambas obras se lleva a cabo la muerte de Blanca y también en los dos autores se describe el mismo escenario que precede a su ejecución. La tragedia de Espronceda concede un papel vital a Enrique de Trastámara por considerarle enamorado de Blanca, que odia tanto a su hermanastro Pedro I como ama y desea a la esposa de este. Los rumores sobre el adulterio de Blanca y su posterior ejecución quedan perfectamente reflejados en el relato de López Soler, no así en el caso de Espronceda. Enrique de Trastámara aparece, pues, como un noble enamorado de la mujer de su hermanastro, que intenta vengar su muerte a toda costa. Él es también el adalid de la conspiración y el ejecutor de Abenfarax, personaje malévolo y verdugo de Blanca de Borbón. De igual forma en ambos autores aparecen los magos que predicen o pronostican entre ambos hermanos un cruento fin, plagado de desgracias y muertes.

La recreación de los hechos históricos referidos a don Enrique de Trastámara

\footnotetext{
Antequera, cuyo argumento versa sobre el gobierno de dicho infante como regente de Castilla durante la minoría de edad de Juan II. Asunto que nos desvela el convulso momento de la historia y cuyos tintes apenas difieren del narrado por López Soler en su novela. Dramas de Hartzenbusch, que aun perteneciendo a épocas anteriores a las rivalidades entre Pedro i y Enrique de Trastámara, ofrecen también concomitancias con no pocos episodios o capítulos de El primogénito de Alburquerque, como monarcas opuestos a enlaces amorosos, personajes infamados, como la calumnia de Sancho referida al Cid, acusado por este personaje infame de haber contado con el traidor Vellido Dolfos para sus propósitos. El tema de las mocedades de un monarca, presente en la novela de López Soler en el arranque de la misma, también lo encontramos en el drama La madre de Pelayo. Material literario presente en numerosos dramaturgos románticos como, entre otros, en Gil de Zárate-Don Álvaro de Luna, Guzmán el Bueno-, Patricio de la Escosura -Jaime el Conquistador-, José María Díaz, precursor en muchos aspectos de Echegaray por sus dramas plagados de suicidios, crímenes, duelos y numerosos episodios truculentos en general -Elvira de Albornoz, Baltasar Gozza, Gabriela de Bergy-, José Francisco Pacheco Los siete infantes de Lara, Bernardo del Carpio-, Jaime Tió -El castellano de Mora, Alfonso el Liberal, El espejo de las venganzas-, Víctor Balaguer -Wifredo el Velloso, Juan de Padilla-, Romero Larrañaga -El gabán del rey-, Eusebio Asquerino -Doña Urraca-. Sin embargo, será Zorrilla quien con mayor prodigalidad escriba sobre temas y asuntos medievales, desde dramas basados, fundamentalmente, en tradiciones y leyendas de esta época, desde la etapa visigótica hasta el reinado de Pedro i el Cruel, como en sus obras, entre otras, El rey loco, El puñal del godo, La calentura, El Eco de Torrente, Sancho García, El caballo del rey don Sancho y El zapatero y el rey.
}

${ }^{6}$ R. Marrast, José Espronceda y su tiempo. Literatura, sociedad y política en tiempos del Romanticismo, Barcelona, Editorial Crítica, 1989, p. 201. 
aparece también en la poco conocida obra de Pedro Sabater -Enrique el Bastardo, conde de Trastámara-, cuyo arranque dramático se inicia con una nota extractada de la Historia de España del padre Mariana que hace alusión al cruento y terrible episodio histórico protagonizado por los dos hermanastros ${ }^{7}$. El drama, dedicado a D. Mariano Roca de Togores, recrea el enfrentamiento entre ambos hermanos y alude a otros personajes que tienen una gran incidencia en El Primogénito de Alburquerque, especialmente el favorito del rey Pedro i el Cruel, Samuel Levi, autor de la compleja trama que acusa a Blanca de Borbón de mantener una relación amorosa con el hermano de Pedro I, don Fadrique, Gran Maestre de Santiago, y personaje que ocuparía un lugar señero en la dramaturgia española gracias a la obra de García Gutiérrez titulada El tesorero del rey, estrenada en 1850. Cabe recordar que estos dos personajes, Samuel Levy y don Fadrique, fueron ejecutados por orden del monarca. Los cuatro primeros actos del drama transcurren en Toledo y en sus inmediaciones, episodios que se acercan más a lo acontecido en la novela de López Soler, pues los dos últimos actos del drama transcurren en el campo de Montiel, a finales del reinado de Pedro I. A diferencia de López Soler, Pedro Sabater se muestra como un escritor defensor de Enrique de Trastámara, pues lo considera un héroe, un ser virtuoso que contrasta con la crueldad de Pedro I, elogiado y presentado al público de la época como un monarca justiciero. De hecho y a pesar de los crímenes cometidos por Pedro I -muerte de doña Leonor de Guzmán, Núñez de León, Ossorio, Blanca de Borbón, entre otros- siempre aparece en los escenarios de la época como un galán justiciero, no como un ser ambicioso y criminal. Esto es lo que denuncia Sabater, de ahí su reivindicación y su clara defensa por los derechos de Enrique de Trastámara. Las rivalidades entre Pedro I y Enrique de Trastámara, así como las desavenencias de los nobles contra el monarca encuentran feliz acogida en numerosos dramas de la época, como en F. J. Foxá, Don Pedro de Castilla (1839), J. M. Huici, Don Pedro el Cruel (1840), J. Rua y Figueroa, Fernán Pérez Churruchao y el Arzobispo D. Suero (1841), M. A. Príncipe, Cerdán, Justicia de Aragón (1841), entre otros ${ }^{8}$.

La novela de López Soler, El Primogénito de Alburquerque, firmada con el

\footnotetext{
7 «Punzaba a D. Pedro la ofensa que se le hacía; a D. Enrique le encendía en cólera, y animaba a la venganza, la sangre que de su madre y hermanos, amigos y parientes derramaron, y los grandes trabajos que el reino padecía», P. Sabater, D. Enrique el Bastardo, conde de Trastámara. Drama histórico en seis actos, Valencia, Imprenta de López y Compañía, 1841, [s. p.]

${ }^{8}$ P. Meregalli, Pietro di Castiglia nella letteratura, Milan/Venecia, La Goliardica, s.a.; G. Moya, Don Pedro el Cruel: Biología, política y tradición literaria en la figura de Pedro I de Castilla, Madrid, Júcar, 1975; R. San Martín, «Un viaje por el mito del rey Cruel: la literatura y la historia después del Romanticismo», Revista de Literatura, 129 (2003), pp. 59-84; M. R. Álvarez Rubio, «Pedro el Cruel», en Leonardo Romero Tobar. Temas literarios hispánicos, Zaragoza, Prensas de la Universidad, 2013, pp. 197-216; véase también el material noticioso sobre el enfrentamiento sobre Pedro I y Enrique de Trastmara y la justificación sucesoria inserto en las monografías siguientes: J. Valdeón Baruque, Pedro i el Cruel y Enrique de Trastámara- ¿La primera guerra civil española?, Madrid, Aguilar-Santillana, 2003 y C. Valdaliso Casanova, Historiografía y legitimación dinástica. Análisis de la Crónica de Pedro I el Cruel, Valladolid, Universidad de Valladolid, 2010.
} 
seudónimo Gregorio Pérez de Miranda, al igual que sus novelas históricas Henrique de Lorena, Jaime el Barbudo y Kar-Osmán o Memorias de la casa de Silva, se publicó a finales de 1833 y principios de 1834 en cuatro volúmenes ${ }^{9}$. Sus novelas editadas con anterioridad incluyen un prólogo en el que su autor explica múltiples aspectos referidos no solo a la intención de su relato, sino también al material noticioso utilizado, a las fuentes históricas. De esta forma el lector o estudioso de su obra encuentra un corpus histórico y literario de sumo interés. Recordemos, por ejemplo, su prólogo a la novela Los bandos de Castilla, considerado por la crítica como un manifiesto romántico de gran trascendencia, fundamentalmente por su incidencia en la novela histórica y en la búsqueda de asuntos referidos a la Edad Media. El Primogénito de Alburquerque no es una excepción en este sentido, aunque la nota introductoria que figura al frente de la misma no tiene la misma relevancia que la de Los bandos de Castilla. Su postura en el prólogo es ecléctica, como ecléctica fue también su postura en lo publicado en El Europeo o en El Vapor, aunque siempre tiende a las excelencias de la escuela romántica más que a la neoclásica. Eclecticismo en su intención, en su forma de presentar la figura de don Pedro y la del conde de Trastámara:

Por supuesto que no fue don Pedro tan perverso como los cronistas lo pintan; pero tampoco procedió con la rectitud extremada que en sus acciones suponen los que, llevados de cierto odio contra la descendencia del conde de Trastámara, se esfuerzan en disculpar sus atropellamientos. Porque si bien es cierto que la aspereza de la reina y las maquiavélicas tramas de los bastardos lo aguijoneaban, exasperaban y endurecían, no deja por otra parte de serlo que había cierta fórmula de juicio desde don Alfonso décimo, en fuerza de la cual debían castigarse los reos, y no a manera de encarnizado pasatiempo y por una simple indicación a sayones, maceros y verdugos ${ }^{10}$.

López Soler se muestra cauto con la historia, pues elogia y censura a ambas facciones. A pesar de ello se decantará por el conde de Trastámara, pues si bien es verdad que el tono elogioso brilla por su ausencia en la novela, no por ello le considera un ser perverso, malévolo, depravado y amoral, como en el caso de Pedro I. Tal como se podrá constatar en las páginas posteriores, su figura, su forma de pensar serán cada

\footnotetext{
${ }^{9}$ El primogénito de Alburquerque, por don Gregorio Pérez de Miranda, Madrid, Imprenta de Repullés, 18331834. Al final del tomo II aparece una nota del editor que comunica a sus lectores la publicación de El doncel de Don Enrique el Doliente, de Mariano José de Larra. Publicación que se llevará a cabo, evidentemente, a partir del cuarto tomo de la obra de López Soler. Las fechas de edición de los respectivos volúmenes son octubre y noviembre de 1833, los dos primeros; el tercero y el cuarto en diciembre de 1833 y enero de 1834, respectivamente. A diferencia de numerosas novelas históricas, El primogénito de Alburquerque no encarta láminas ni grabados alusivos a los personajes o sucesos históricos, solo minúsculas estampaciones de objetos o adornos en la finalización de un determinado capítulo, salvo el grabado que figura al final del capítulo segundo del primer tomo, referido al famoso astrólogo Fez-Alhamar. Dicho sabio pronostica al entonces joven y futuro monarca un final plagado de muertes violentas, incluida la suya, si no cumple en un futuro sus promesas. El grabado alude a objetos propios de la astrología, las matemáticas y a la ciencia en general, fundamentalmente a la astrología judiciaria, la aplicada a los pronósticos.
}

${ }^{10}$ López Soler, El primogénito, ob. cit., I, pp. v-VI. 
vez más odiosas ante los ojos del lector, convirtiéndose el monarca en su ser antónimo de la virtud, en un rey que no merece ser respetado ni honrado por sus súbditos; de ahí que López Soler pudiera tener en cuenta aquellos versos del Rimado de Palacio que hacen alusión a la política y a las enseñanzas del gobierno. Es bien conocida la excelente y sutil definición del dictado y oficio del monarca en versos de Pérez de Ayala, autor citado por López Soler en sus escritos: «Este nombre de rey de buen regir desçiende, /Quien ha buena ventura, bien así lo entiende, /El que bien a su pueblo govierna e defiende, / Este es rey verdadero, tírese el otro dende ${ }^{11}$.

Versos que figuran en el epígrafe Del governamiento de la república y en los que se alude directamente a las obligaciones de los reyes y nobles con respecto a sus súbditos, cultura y etnia. Pérez de Ayala en sus versos hace referencia a una serie de aspectos que subyacen en la novela de López Soler, especialmente en el tratamiento referido a los judíos, «aparejados para beber la sangre de los pobres cuitados» ${ }^{12}$. Cabe recordar al respecto la figura del judío Samuel Levy, personaje omnipresente en El primogénito de Alburquerque y el más odiado por los cristianos, tanto por su poder y crueldad como por su falta de honor y capacidad para desvirtuar los hechos en favor suyo. Actúa como una especie de privado, manejando las arcas del reino a su antojo ${ }^{13}$. La lucha entre Pedro I y Enrique in siempre fue considerada en el Romanticismo como una lucha entre hermanos, al igual que ocurrió en España al fallecer Fernando vII; sin embargo, también cabe pensar en las dificultades económicas de la época, en las rivalidades entre nobleza y monarquía, cuyos subsidios acrecentaban o menguaban el poder económico del monarca. Se regulan las aduanas, los almojarifazgos, diezmos marítimos, la participación en el corso y cabalgadas, aumentando y perfeccionando las causas fiscales.

\footnotetext{
${ }^{11}$ Poetas castellanos anteriores al siglo XV. Colección hecha por Don Tomás Antonio Sánchez, continuada por el Excelentísimo Señor Don Pedro José Pidal, considerablemente aumentada e ilustrada, a vista de los códices y manuscritos antiguos, por Don Florencio Jover, Madrid, BAE, 1864, p. 432, estrofa 235.

${ }^{12}$ Idem, estrofa 244.

${ }^{13}$ La figura del judío Samuel Levy se erige como la piedra angular de los hechos narrados. Favorece la guerra contra el conde de Trastámara gracias a la riqueza acumulada. Aconseja a Pedro I el Cruel en los asuntos de estado y actúa como un auténtico mentor en decisiones vitales relacionadas con la nobleza. Está siempre presente en el mundo de ficción y su actuación es constantemente odiosa. Propala infundios sobre la figura de Blanca de Borbón, de don Fadrique, hermano del conde de Trastámara. Insta a Pedro I a que cometa todo tipo de infamias. Teje una red de espionaje que le permite conocer los planes de sus adversarios. Su astucia y proverbial inteligencia le permiten acumular riquezas y disponer en múltiples ocasiones de la voluntad del monarca. Se muestra siempre atento, complaciente, respetuoso, servicial a fin de conseguir sus propósitos. De igual forma se comporta cruel, despiadado, déspota, implacable con sus enemigos. Es odiado por los cristianos y sufrirá persecución por el pueblo como consecuencia de sus perversos hechos. Al final de la novela morirá a instancias de su protector, Pedro I, al descubrir la falsedad y red de mentiras en detrimento de sus seres más próximos y queridos. Conocedor el monarca de las relaciones amorosas entre el primogénito de Alburquerque y María de Padilla -padres de un niño atribuido a doña Blanca de Borbón y al hermanastro del rey, don Fadrique, gracias a las mentiras de Samuel Levy- morirá de una manera «asaz fea de contar», López Soler, El primogénito, ob. cit., IV, p. 280.
} 
Los impuestos derivados de transacciones comerciales eran más fiables y seguros que los votados en las Cortes, de ahí que se reorganizara el sistema recaudatorio con la creación y formación de tesoreros y recaudadores. Esto no lo entendió López Soler, ni, tampoco, sus coetáneos. De hecho, Pedro I, en El primogénito de Alburquerque, actúa de forma inteligente, pues para llevar a cabo esta nueva organización fiscal recurrirá a las personas más aptas, inteligentes y eficaces para asumir los cargos, dando entrada a los judíos, tal como sucedió en la época en que transcurren los sucesos de su novela. De hecho, el sistema cerrado de las clases sociales se resquebraja, ya que los monarcas buscaron las personas más competentes y aptas para los cargos. Por ello es por lo que los judíos formaron parte de la administración del estado, ocupando puestos relevantes y claves en la administración, adquiriendo bienes nobiliarios gracias a los préstamos concedidos. Esta verdad histórica aparece en la novela, pero distorsionada, no como un hecho real, histórico, desde el punto de vista de las dificultades económicas que obligarían a los reyes a iniciar una evolución fiscal al implantar los impuestos indirectos, procedentes del comercio y monopolios - convenios realizados entre los mercaderes para vender los géneros a un determinado precio-, sino como un rasgo que determina la incompatibilidad entre judíos y cristianos, la imposibilidad de vivir con quienes disponen de la riqueza en detrimento de los más débiles, los cristianos que, al igual que los nobles, están bajo su poder mediante empréstitos o préstamos solicitados a los judíos para costear la guerra y mantener económicamente a un ejército numeroso.

En la novela de López Soler se alude directamente a las fuentes literarias e históricas utilizadas para novelar la historia de Pedro i y las «maquiavélicas tramas de los bastardos». Él mismo comunica al lector lo siguiente:

Partiendo de estos principios, y tirando como una línea imparcial entre las acusaciones de Ayala y las apologías del conde de la Roca y el licenciado Ledo del Pozo, consagraremos nuestra pluma a pintar la verdadera índole de aquel célebre monarca, no menos que el original carácter de las revueltas que distinguen su reinado ${ }^{14}$.

A continuación López Soler señala su preocupación por no estar a la altura de sus lectores, a pesar de haberse entregado por completo al estudio y consulta de las publicaciones más señeras sobre Pedro I y su enfrentamiento con sus hermanastros. Las referencias bibliográficas citadas sucintamente por López Soler en su brevísimo prólogo de dos páginas y media nos remiten a don Pedro López, a su obra Crónica de los reyes de Castilla D. Pedro, D. Enrique II, D. Juan I y D. Enrique III, publicada por el célebre editor Sancha en 1779-1789 bajo el título Colección de Crónicas y Memorias de

\footnotetext{
${ }^{14}$ Ibidem, I, p. vI.
} 
los Reyes de Castilla ${ }^{15}$. Dicha colección de crónicas comprende también otros reinados hasta configurar una publicación de siete volúmenes ${ }^{16}$. Sin lugar a dudas, López Soler utilizaría esta publicación, celebérrima en su época y la única que estaba a su alcance. Años más tarde dicha edición de las crónicas de López de Ayala pasaría a un segundo plano, siendo sustituida por la clásica impresión de Cayetano Rosell en 1875 para la Biblioteca de Autores Españoles ${ }^{17}$. La siguiente fuente histórica utilizada por López Soler, la del conde de la Roca, se refiere a don Antonio Vera y Figueroa, poseedor de dicho título nobiliario y autor de la obra El Rey D. Pedro defendido, ofrecido a la Majestad del Rey Don Felipe IV ${ }^{18}$. Se trata de un opúsculo, de suma rareza bibliográfica, publicado en el año 1647, que analiza la figura de Pedro i como un monarca justo, legítimo y equitativo. La tercera y última referencia bibliográfica sobre las fuentes históricas utilizadas por el novelista corresponde al licenciado Ledo del Pozo. López Soler se refiere a la obra titulada Apología del rey Don Pedro de Castilla, conforme a la crónica verdadera de D. Pedro López de Ayala ${ }^{19}$, publicada en 1780. Obra accesible a la generación del escritor a diferencia del estudio del mismo Ledo del Pozo titulada Historia de la nobilísima villa de Benavente, publicada después de la primera edición de El primogénito de Albuquerque ${ }^{20}$.

Ramón López Soler suele ocultar parte de las fuentes bibliográficas utilizadas para la elaboración de sus novelas en los prólogos que preceden al relato. A través del cotejo realizado entre los episodios más relevantes de El primogénito de Alburquerque y la Colección de romances castellanos anteriores al siglo XVIII, llevada a cabo por Agustín Durán, podemos observar las concomitancias existentes entre la peripecia argumental de la novela y lo vertido en dicha recopilación de romances. No olvidemos tampoco

${ }^{15}$ P. López de Ayala, Crónicas de los reyes de Castilla D. Pedro, D. Enrique II, D. Juan I, D. Enrique III, Madrid, Sancha, 1779-1880, 2 vols.

${ }^{16}$ En los siguientes volúmenes se editan la Crónica de D. Pedro Niño Conde de Buelna, por G. Díez de Gámez; Historia del Gran Tamorlan y un breve discurso de G. Argote de Molina; Sumario de los reyes de España, por el despensero mayor de la reyna Doña Leonor, 1782; Memorias históricas de la vida y acciones del rey D. Alfonso VIII el Noble, recogidas por el marqués de Mondexar, 1783; Crónica de D. Álvaro de Luna; Seguro de Tordesillas, por D. P. Fernández de Velazco; Libro del Passo honroso, defendido por Suero de Quiñones. Copilado por Fr. Juan de Pineda, 1783-84; Crónica del rey D. Alfonso el onceno de este nombre, 1787; Crónica de D. Enrique el quarto de este nombre, por D. Enrique del Castillo; Coplas de Mingo Revulgo, por R. de Cota, glosadas por H. del Pulgar; Carta del levantamiento de Toledo en 1467, 1787.

${ }^{17}$ Crónicas de los reyes de Castilla desde Don Alfonso el Sabio, hasta los católicos Don Fernando y Doña Isabel. Colección ordenada por don C. Rosell, Madrid, Rivadeneyra, Editor, BAE, 1875.

${ }^{18} \mathrm{~J}$. A. de Vera y Figueroa, El Rey D. Pedro defendido, ofrecido a la Majestad del Rey Don Felipe IV, nuestro señor, por..., Conde de la Roca, Vizconde de Sierra-Brava, Señor de las Villas de Torre-mayor, Enguidanos y la Pesquera, Comendador de La-Barca en la Orden de Santiago, Madrid, Francisco García, impresor del Reino, 1647.

${ }^{19}$ J. Ledo del Pozo, Apología del rey Don Pedro de Castilla, conforme a la crónica verdadera de D. Pedro López de Ayala, Madrid, Imprenta de Hernández, s. a. [1780].

${ }^{20} \mathrm{~J}$. Ledo del Pozo, Historia de la nobilísima villa de Benavente con la antigüedad de su Ducado, principio de su Condado, sucesión y hazañas heroicas de sus condes, Zamora, por Vicente Vallecillo, 1853. 
que su obra crítica -Discurso ${ }^{21}$ - , publicada en el año 1824, fue determinante tanto para la novela de López Soler como para la revalorización del teatro áureo y la poesía popular. Cabe recordar también que en dicho año se publicó el primer volumen de la colección de Romances y en años posteriores, hasta 1832, los cuatro volúmenes restantes $^{22}$. Es bien conocida la polémica que provocó el Discurso de Durán, analizada por hispanistas en estas últimas décadas, como en los estudios de Caldera ${ }^{23}$, Shaw $^{24}$ y Gies $^{25}$. Cabe recordar también que Larra se unió a los elogios del Discurso, en la línea de Nicolás Böhl de Faber, Quintana y Carnerero, publicando un artículo en $1833^{26}$ en defensa del ensayo de Durán momentos antes de que apareciera su novela El doncel de don Enrique el Doliente, citada en la conclusión del volumen segundo de la novela de López Soler, noviembre de 1853: «La novela que seguirá al primogénito de Alburquerque será El doncel de don Enrique el Doliente, de Don Mariano José de Larra» ${ }^{27}$. Es evidente que los novelistas de la época, como en el caso de los colaboradores de la Colección de novelas históricas originales españolas fundada por Repullés, conocían no solo la polémica entre los defensores y detractores del ensayo de Durán, sino también su Colección de romances editada y distribuida por el célebre librero Amarita, cuyos puntos de venta en Madrid y provincias posibilitaban una rápida distribución de las publicaciones.

El romance perteneciente al número novecientos ochenta del romancero de Durán, titulado Resumen de la historia del rey Pedro el Cruel (de Lorenzo de Sepúlveda) parece el argumento de la novela El primogénito de Alburquerque, pues se registra la casi totalidad de los episodios históricos referidos en el romance, como las imputaciones falsas sobre Blanca de Borbón, acusada de adulterio, de mantener relaciones con Fadrique, Gran Maestre de Santiago. Presencia también en el romance de episodios sobre María de Padilla y sobre los crímenes de Pedro i y sus venganzas personales.

\footnotetext{
${ }^{21}$ Discurso sobre el influjo que ha tenido la crítica moderna en la decadencia del Teatro Antiguo Español, y sobre el modo con que debe ser considerado para juzgar convenientemente de su mérito peculiar. Por D. A. D., Madrid, Imprenta de Ortega y Compañía, 1828.

${ }^{22}$ A. Durán, Colección de romances castellanos anteriores al siglo xvIII, Madrid, Amarita y Aguado, 1828-1832, 5 vols. Bajo esta portada común figuran los cinco volúmenes de la Colección de romances moriscos, 1828; Romancero de romances doctrinales, 1829; Cancionero y romancero de coplas, 1829; Romancero de romances caballerescos e históricos, 1832 [2 vols.].

${ }^{23}$ E. Caldera, Primi manifesti del romanticismo spagnolo, Pisa, Istituto di Letteratura Spagnola e HispanoAmericana dell'Università di Pisa, 1962.

${ }^{24}$ A. Durán, Discurso sobre el influjo que ha tenido la crítica moderna en la decadencia del Teatro Antiguo Español, y sobre el modo con que debe ser considerado para juzgar convenientemente de su mérito peculiar. Introduction and notes by D. L. Shaw, University of Exeter, 1973.

${ }^{25}$ D. T. Gies, Agustín Durán. A Biography and Literary Appreciation, London, Tamesis Books, 1975.

${ }^{26}$ M. J. de Larra, «Discurso sobre el influjo que ha tenido la crítica moderna en la decadencia del teatro antiguo español, y sobre el modo con que debe ser considerado para juzgar convenientemente su mérito peculiar, por D.A.D.», Revista Española, 2 de abril (1833), p. 464.
}

${ }^{27}$ R. López Soler, El primogénito, ob. cit., II, p. 251. 
Alianzas entre nobles para derrocar a Pedro i del trono y otros episodios recreados por López Soler en su novela están plasmados en el romance citado. Traslación idéntica del romance a la novela es también el episodio referido a las alianzas de estado. Don Enrique de Trastámara, por ejemplo, se declara defensor de Blanca de Borbón y trata de salvarla a toda costa, como en el romance:
Contra ella hizo proceso;
A sus grandes ha pesado, Mayormente a Don Enrique
Y también a sus hermanos.
Determinan todos juntos
De poner la Reyna en salvo.
Porque estaba inocente
De lo que le es levantado 28 .

La relación de nobles que aparece en el romance citado concuerda en gran medida con la descripción que de los mismos se lleva a cabo en la novela de López Soler, salvo, precisamente, la figura del protagonista, el primogénito de Alburquerque, que brilla por su ausencia en el romance. La sucesión de los hechos descritos en el romance concuerdan también con el relato de López Soler. Incluso en ambos casos se describe la crueldad del monarca y sus crímenes de forma gradual, cronológicamente, de forma sucinta en el romance y ampliamente recreada según la estética romántica en la novela. Tanto en la novela como en el romance Resumen de la historia del rey don Pedro el Cruel la muerte del monarca está justificada por la crueldad, aunque en El primogénito de Alburquerque lo que prima es la felicidad del protagonista y de sus seres más queridos y próximos, apartándose de la vida cortesana y jurando fidelidad a Enrique de Trastámara:

Pero así que los representantes de la nación castellana reunidos en cortes, declararon en Burgos la caducidad del gran tirano violador [Pedro i el Cruel] de las leyes, desheredando a sus descendientes del cetro que dieron a Trastámara, no vaciló don Martín [el primogénito de Alburquerque] en reconocer sus derechos procedente de legítimo origen, y volvió a Castilla a prestar al electo rey el juramento de fidelidad, a que no faltó jamás ${ }^{29}$.

López Soler era conocedor también de los romances recopilados por Durán, como el titulado Romance de cómo la reina Blanca, mujer del rey de Castilla don Pedro,

\footnotetext{
${ }^{28}$ Las citas correspondientes al romancero de Durán están tomadas de la citada edición llevada a cabo en 1861 por la Biblioteca de Autores Españoles, ob. cit., II, p. 47.

${ }^{29}$ R. López Soler, El primogénito, ob. cit., Iv, pp. 282-283. En el romance se alude también a la batalla de Montiel en el que Enrique de Trastámara acabó con la vida de Pedro I, y se incide, una vez más, en la crueldad del monarca. El final del romance coincide también con el de la novela, pues en ambos casos se entroniza como nuevo rey al conde de Trastámara: «Mas estando en Montiel / lo ha muerto ese su hermano: / Don Enrique se llamaba, / y por rey se ha coronado. /Fue España muy alegre, / a Dios está alabando: / los que él viviendo eran tristes, / con su muerte se han gozado», A. Durán, Colección de romances, ob. cit., II, p. 45 .
} 
tuvo un hijo de su cuñado don Fadrique, y de cómo cuando don Enrique II llegó a reinar, le hizo almirante de Castilla. Las relaciones entre don Fadrique y doña Blanca ocupan un lugar señero en la novela, aunque su final difiere en el relato, pues ambos mueren a instancias de don Pedro I. Los romances Mata don Pedro a su hermano don Fadrique y prende a doña Blanca su esposa, porque lloraba la muerte de su cuñado y Llora doña Blanca el rigor con que la trata su esposo el rey don Pedro, atribuyéndolo a hechizo que le dio la Padilla, guardan también concomitancias con el relato de López Soler, fundamentalmente con la muerte de Fadrique, hermano de Enrique de Trastámara y hermanastro de Pedro i el Cruel, y con el brevísimo desposorio entre Blanca de Borbón y el rey. El resto de romances anónimos numerados con las cifras novecientos sesenta y ocho y novecientos sesenta y nueva tratan de nuevo sobre Blanca de Borbón y su presidio, episodio, este último, ampliamente tratado en El primogénito de Alburquerque. Los cinco romances siguientes inciden también en la novela. Así, por ejemplo, el titulado Visión que tuvo el rey don Pedro para ver de convertirse a Dios coincide por completo con los episodios más crueles cometidos por el monarca y se asemeja por completo con el inicio de la novela. El final del romance sintetiza también las premoniciones que un astrólogo árabe, Fez-Alhamar, lleva a cabo en la novela sobre Pedro I, vaticinándole un final trágico si gobierna de forma injusta y mata sin justicia. Solo varía la fórmula utilizada, pues en el romance se recurre a una visión por parte de Pedro I, y en el relato, tal como se ha indicado, a una predicción. El tema del romance fue tomado de la tradición en la que Pedro i tiene un aviso del cielo para impedirle que mate a su esposa doña Blanca de Borbón. Lope de Vega en su comedia El Rey Don Pedro i en Madrid y el infanzón de Illescas, y Moreto en su obra El Rico-home de Alcalá, introducen varios lances acaecidos a este rey. Al final del romance la visión maravillosa le comunica su fatal destino: «Por tu culpa y mal gobierno / Y tu hermano Don Enrique/ Te habrá de heredar tu reino: / Morirás a puñaladas / Tu casa será el infierno / Todo esto recontado / Desapareció el bulto negro» ${ }^{30}$.

Sobre el enriquecimiento de los Padilla y su influencia en los asuntos de estado, el romancero ofrece también un material noticioso de gran valor para López Soler. La muerte de Blanca de Borbón pudiera estar tomada del célebre romance anónimo, inserto en el Romancero General, titulado A ruego de la Padilla hace el Rey don Pedro matar a su esposa doña Blanca, en el que el monarca actúa como un tirano y con una crueldad inhumana al ordenar la ejecución de su esposa. Episodio que también tiene lugar en

\footnotetext{
${ }^{30}$ Ibidem, II, p. 38. El citado romance sintetiza también los episodios más relevantes de la novela. El bulto negro que aparece ante los ojos de Pedro i el Cruel le comunica a grandes voces lo siguiente: «Morirás, el rey Don Pedro, / que mataste sin justicia / los mejores de tu reino: / Mataste tu propio hermano / El Maestre, sin consejo, / y desterraste a tu madre: / A Dios darás cuenta d'ello. / Tienes presa a Doña Blanca, / enojaste a Dios por ello, que si tornas a quererla / darte ha Dios un heredero. / Y si no, por cierto sepas / te vendrá desmán por ello [...]» (idem).
} 
la novela de López Soler, pero de forma truculenta, dramática, sádica, pues su cabeza, decapitada, es arrojada desde lo alto de un palacete, esparciéndose sus sesos por el pavimento.

Otras ocultaciones de fuentes literarias por parte de López Soler pudiera ser la Historia General de España del padre Mariana, convertida en una especie de libro de cabecera tanto para dramaturgo como para novelistas de la época romántica. La excelente edición de Joaquín Ibarra, publicada en 1780, fue hasta la aparición de la Historia General de España de Modesto Lafuente (1850-1869) la más utilizada por los escritores adscritos al Romanticismo. De hecho, el propio López Soler utilizó la edición de Ibarra en su novela Los bandos de Castilla para recrear la corte de Juan II de Castilla y los hechos de su privado el condestable don Álvaro de Luna. López Soler utiliza con toda seguridad la edición de Antonio Sancha ${ }^{31}$. publicada en dos volúmenes en los años 1779-1780. La última edición que precedió a esta fue en el año 1591, impresa con licencia del Consejo Real en la ciudad de Pamplona por Pedro Porralis. Ejemplar de suma rareza bibliográfica, al contrario de la edición de Antonio Sancha, cuya tirada editorial fue proverbial. De hecho, hasta la aparición de la colección de crónicas de los Reyes de Castilla, ordenada por Cayetano Rosell, año $1875^{32}$. la edición de Sancha fue la utilizada por los escritores del primer y segundo tercio del siglo XIX.

López Soler lleva a cabo una detenida lectura de la Crónica de López de Ayala. El testimonio sobre los Alburquerques procede, fundamentalmente, de los datos fechados en los años 1353, 1354 y 1355. Como es bien sabido López Soler estructura sus obras por fechas, desde el primer año del reinado de Pedro I, 1350, hasta su muerte a manos de Enrique de Trastámara, 1369. En el año cuarto, 1353, se ofrece un material noticioso sobre don Juan Alfonso de Alburquerque, padre del protagonista de la novela, su hijo primogénito Martín, fundándose López Soler en los capítulos «Como don Juan Alfonso de Alburquerque llegó a Torrijos, e trajo consigo a Don Juan de La Cerda», "Como don Juan Alfonso de Alburquerque acuciaba que pelease el Rey con el Conde» $\mathrm{y}$ «Del consejo que don Juan Alfonso de Alburquerque, e Maestre de Calatrava avieron con los Reyes Doña María madre del Rey, e Doña Blanca de Borbón su mujer, después que el Rey partió de Valladolid, e de lo que acaesció por esto», capítulos de la Crónica correspondientes al año 1354. Los capítulos pertenecientes al año 1355 recogen también un conjunto trascendental de hechos para la elaboración de la peripecia argumental, fundamentalmente los titulados «Como se trató avenencia entre el conde

\footnotetext{
${ }^{31}$ Crónica de los Reyes de Castilla, desde don Alfonso el Sabio, hasta los católicos don Fernando y doña Isabel, con las enmiendas del Secretario Gerónimo Zurita y las correcciones y notas de Eugenio de Llaguno, Madrid, Imprenta de S. Agustín Sancha, 1779-1780.

${ }^{32}$ Crónica de los Reyes de Castilla, desde don Alfonso el Sabio, hasta los católicos don Fernando y doña Isabel. Colección ordenada por Don C. Rosell, Madrid, Rivadeneyra, BAE, 1875.
} 
Don Enrique e con el Maestre Don Fadrique, e se avinieron», «De otra pleitesía que el Conde y el Maestre, e Don Juan Alfonso movieron al Infante Don Pedro de Portugal», «Como llegaron nuevas al Rey que el Conde Don Enrique, e el Maestre Don Fadrique, e los que había dejado por fronteros sobre Alburquerque que eran avenidos con Don Juan Alfonso» y «Como el Rey tomó algunos lugares de Don Juan Alfonso de Alburquerque». A partir del 28 de septiembre de 1354, año quinto del reinado de don Pedro, Pérez de Ayala prescinde de su figura. Cabe recordar que fue canciller mayor de Castilla, mayordomo mayor de la reina María de Portugal -esposa de Alfonso $\mathrm{XI}-\mathrm{y}$, entre otros puestos trascendentales, ayo y mayordomo mayor de los infantes don Fernando y don Pedro, hijos del rey Alfonso xI. Solo tuvo un hijo del matrimonio eclesiástico, don Martín, el primogénito de Alburquerque, el protagonista de la novela. La Crónica de Pérez de Ayala sobre Pedro i prescinde de las excelentes relaciones entre don Pedro I y don Martín. De hecho, el arranque de la novela se inicia en Sevilla, con la aparición del todavía infante don Pedro y don Martín, amigos, confidentes y hermanados por intereses familiares. Como es bien sabido, estuvo presente en los momentos más cruciales del reinado de Pedro i durante su vida, distanciándose ambos sobremanera y produciéndose un gran deterioro en las relaciones entre el monarca y los Alburquerque, hasta el punto que tanto la historia como la ficción dan por sentado que el monarca envenenó a Juan Alfonso de Alburquerque y a su propio hijo.

En la novela de López Soler se evidencia una gran concomitancia entre lo descrito por López de Ayala en su Crónica y lo apuntado en la novela, aunque López Soler da rienda suelta a los hechos que rodearon la muerte de Alburquerque, envenenado por el médico del monarca al darle un bebedizo de hierbas venosas. Sucesos que se ofrecen tanto en la Crónica como en la novela. Sin embargo dicho testimonio dará pie a otro suceso referido al entierro del noble Alburquerque, retrasado sine die hasta que sus seguidores y, principalmente, Enrique de Trastámara no consiguieran la victoria contra Pedro I el Cruel ${ }^{33}$. Su ataúd, que siempre presidía la vanguardia de los ejércitos contrarios al monarca, fue sepultado una vez conseguida la victoria en el monasterio de Santa Espina, en Castromonte, provincia de Valladolid. Este hecho fantástico, maravilloso, pues el cadáver habla por boca de su mayordomo, don Ruiz-Díaz Cabeza de Vaca, es un episodio recreado profusamente por López Soler en su novela. Los principales sucesos novelescos relacionados con Enrique de Trastámara y Juan Alfonso de Alburquerque se refieren en un principio a su implicación en el asesinato de Leonor de Guzmán, la amante de Alfonso xI y madre de los bastardos. Relación también a los hechos acaecidos durante los años 1353 y 1354 en el reinado de Pedro I,

\footnotetext{
${ }^{33}$ J. Salazar y Acha, La casa del Rey de Castilla y León en la Edad Media, Madrid, Centro de Estudios Políticos y Constitucionales, 2000; L. Fernández Suárez y J. Reglá Capitol, «España cristiana. Crisis de la Reconquista. Luchas civiles», en Historia de España de Menéndez Pidal, Madrid, Espasa Calpe, 1991, XIV, pp. 3-42 y 99-158.
} 
estructurados de forma semejante a la Crónica de López de Ayala, fundamentalmente con los episodios referidos a la celebración de su boda en Valladolid con doña Blanca de Borbón, en la que el conde de Trastámara quiso entrar en la ciudad con un nutrido ejército. Hecho histórico que más parecía un reto que un fraternal homenaje. Tras un breve parlamento entre don Pedro y don Enrique, en el que pactaron las paces, el de Trastámara incumplió la promesa, aliándose con Alburquerque, enemigo de Pedro I en estas fechas. La novela también recrea las alianzas de Fernando de Castro, señor de Galicia, y Juan de la Cerda. Nobles que se unen a Enrique de Trastámara y a Alburquerque. Se noveliza la toma de Toledo y la proclamación de doña Blanca de Borbón como reina. Pedro I será hecho prisionero por los sublevados, sufriendo un trato vejatorio que nunca olvidaría. Disuelta la liga, el bando opositor, comandado por don Enrique de Trastámara, llevaría a cabo una tenaz persecución y cruenta matanza de judíos. Hechos ampliamente comentados en la novela, engarzados también con el mundo de ficción, no como una digresión histórica, sino infartados con el acontecer de los hechos. La huida de Enrique de Trastámara ante la llegada de las tropas de Pedro i el Cruel, las contiendas entre Castilla y Aragón y las alianzas entre ambos reinos con Inglaterra y Francia, tras el rechazo de Pedro i a Blanca de Borbón, serán aspectos tomados directamente de la Crónica de López de Ayala ${ }^{34}$. La novela finaliza, precisamente, con la entrada de los franceses mandados por Beltrán Du Guesclin en clara alianza y apoyo al conde de Trastámara y al también aliado rey de Aragón. La novela, aunque no precisa la fecha, concluye en 1369, con la victoria de Trastámara y su posterior coronación como rey de Castilla en Burgos.

\footnotetext{
${ }^{34}$ López Soler recrea en El primogénito de Alburquerque numerosos capítulos en los que la Crónica de López de Ayala hace hincapié en la figura de Enrique de Trastámara, como en los acaecidos, en un principio, durante los años 1354 y 1355. Los capítulos «De las pleitesías que en el Conde Don Enrique, e Don Juan Alfonso [de Alburquerque] troxieron con don Don Fernando de Castro»; «Como el Conde Don Enrique, e Don Juan Alfonso [de Alburquerque] y don Fernando de Castro se juntaron en uno, e lo que acaesció en este tiempo» $\mathrm{y}$ «Como los infantes de Aragón se avinieron con el Conde Don Enrique, e con Don Juan Alfonso» [de Alburquerque\}, guardan estrecha relación con los hechos narrados. Determinados capítulos de la Crónica correspondientes a los años 1355, 1360, 1366, 1367 y 1369 también son tenidos en cuenta por López Soler para entender los graduales pasos de Enrique de Trastámara hasta la muerte de su hermanastro Pedro I, como los titulados, entre otros, «Como el Conde Don Enrique, e el Maestre su hermano vinieron a Toledo, e lo que acaeció»; «Como el Rey quisiera pelear con el Conde y Maestre sus hermanos, e como ovo sobre ello su Consejo, e como prisó a la Reyna Doña Blanca su mujer»; «Como el Rey hizo matar a algunos en Toledo, e prender a otros»; «Como supo el Rey que el Conde Don Enrique se aparejaba para entrar en Castilla»; «Como el Rey peleó con el Conde Don Enrique e con el Conde de Osona, e los desbarató». El año decimoséptimo del reinado de Pedro I, 1366, es rico en lances entre el monarca y su hermanastro don Enrique, alusivos, en su mayoría a alianzas con Francia y su coronación en Burgos. También la toma de la ciudad de Toledo y batallas entre dichos bandos nobiliarios rivales captan la atención de López Soler al final de su novela, aunque de forma sucinta, pero precisa. El novelista sigue también a pie juntillas el material noticioso sobre las relaciones entre Pedro I y Juana de Castro, viuda de Diego de Haro y hermana de los influyentes nobles gallegos Alvar Pérez de Castro, recién incorporados al bando de los rebeldes. Como es bien sabido por la Crónica de Pérez de Ayala, el rey propuso a la dama el matrimonio y como esta se resistiese pidió a los obispos de Ávila y Salamanca que declarasen la pública nulidad de su boda con doña Blanca de Borbón.
} 
Llama la atención en sumo grado el anacronismo histórico cometido por López Soler con respecto al protagonista de la novela, don Martín Gil, pues su muerte se produce en el año 1365, tal como se constata en la Crónica de López de Ayala en el capítulo IV, titulado Como el Conde Don Enrique se aparejaba para entrar en Castilla:

E en este tiempo el Rey Don Pedro era en Sevilla, e sabía desto, e enviaba sus cartas por todo su Regno a les apercibir que se ayuntasen todos con él. E en este año murió en Sevilla, Don Martín Gil, Señor de Alburquerque, fijo de Don Juan Alfonso e Doña Isabel su mujer, e decían que morió con hiervas que le dieron ${ }^{35}$.

Testimonio que se repite en monografías clásicas referidas a nobles que militaban en la frontera, en villas importantes durante la Reconquista, como en el caso del protagonista de El primogénito de Alburquerque, adelantado en Lorca: «[...] Martín Gil de Alburquerque, a quien teniéndole en renes el Rey Don Pedro el Cruel, dicen que mandó quitar la vida con veneno» ${ }^{36}$. Pese a estos datos, López Soler concluye su novela de forma bien distinta, pues tras prestar juramento de fidelidad a Enrique de Trastámara, al que no faltó jamás, se trasladaría con su esposa Margarita a

la tranquila mansión de la casa paterna, y fueron a vivir en el castillo de Alburquerque. Allí, como esposos amantes, y rodeados de bella y numerosa posteridad, gozaron completamente la mayor dicha que puede el cielo conceder a nuestra imperfecta naturaleza humana, que es la de contentarse con la propia suerte, sin anhelar jamás otra mejor ${ }^{37}$.

Cabe señalar, finalmente, que la novela de López Soler ofrece al lector varias lecturas, pues la trama argumental discurre por diversas líneas que si bien se circunscriben a un determinado contexto histórico, los personajes que pueblan la acción se yerguen como protagonistas, con personalidad propia, como en el caso de los hijos habidos entre Alfonso xI y su amante doña Leonor de Guzmán, los bastardos. Otro tanto sucede con doña Blanca de Borbón y el primogénito de Alburquerque, don Martín, y el monarca Pedro I, pues constituyen también una especie de triángulo amoroso de intensa emoción, captando la atención del lector desde el inicio del relato hasta el desenlace final. El judío Levy o el amplio mundo de criados, palafreneros, sirvientes de confianza, constituyen también parte esencial del relato, aunque es obvio que su conducta y hechos están íntimamente ligados al protagonista, a Martín Gil, el primogénito de Alburquerque, y a don Pedro i el Cruel. Tampoco se puede olvidar el espacio urbano de la novela, descrito con fidelidad por López Soler y engarzado con gran perfección en los numerosos hechos históricos de la época. Este último aspecto

\footnotetext{
${ }^{35}$ A. Durán, Colección de romances, ob. cit., p. 536.

${ }^{36}$ P. Morote, Antigüedad y blasones de la ciudad de Lorca e Historia de Santa María de las Huertas que el Rey Don Alfonso el Sabio trajo para su Conquista, y defensa, año de 1242, Murcia, Francisco Joseph López Mesnier, 1741, Part. II, Lib. I, Cap. XIX, p. 243.

${ }^{37}$ R. López Soler, El primogénito, ob. cit., vol. IV, p. 283.
} 
y los anteriores actúan con identidad propia, infartados en la acción con acierto y excelente pulso literario. Item más, los recursos y asuntos literarios utilizados por López Soler servirán de base a posteriores obras literarias, pues no se debe olvidar que El primogénito de Alburquerque se publicó antes que las novelas de Larra, Cortada, Escosura, Ochoa, entre otros, en la prestigiosa Colección de novelas históricas originales españolas ${ }^{38}$. Bien es verdad que el impresor Cabrerizo, editor de Los bandos de Castilla había adquirido gran prestigio en Valencia, como Bergnes de las Casas en Barcelona, pero el alcance, difusión y remuneración económica eran de mayor calado en Repullés, fundamentalmente en el inicio del segundo tercio del siglo XIX.

La relación entre el futuro rey de Castilla, Enrique de Trastámara, y los Alburquerques está siempre presente en la novela de López Soler, consciente el autor de la importancia de estos personajes históricos en el devenir de los hechos novelescos. El conde de Trastámara aparece en el relato tanto de forma implícita como explícita, bien a través de la perspectiva de los afines de Pedro I, o de sus detractores. Ópticas divergentes que discurren a través de la esposa del Alfonso XI, María de Portugal, o su amante Leonor de Guzmán, madre de Enrique de Trastámara. Mujeres descritas con dispar criterio, pues la reina doña María de Portugal se muestra por regla general como una mujer severa, rigurosa, siniestra, mientras que doña Leonor de Guzmán es descrita desde una óptica distinta, como amante sincera del monarca y madre sensible e indulgente. La rivalidad entre Pedro I y su hermanastro, Enrique de Trastámara, subyace en la novela de forma ininterrumpida, condicionada por sus alianzas y enfrentamientos, por sus pactos con sectores nobiliarios en detrimento del poder de Pedro I. López Soler describe a don Enrique como un ser astuto, que admira el valor de sus rivales. No es malicioso y hace gala de un alto sentido del honor. Su trasiego por ciudades y villas, sus victorias y derrotas, sus alianzas con Aragón y Francia son

\footnotetext{
${ }^{38}$ López Soler hace gala en su novela de un riquísimo material noticioso sobre ambos aspectos. Así, en lo que respecta a los recursos literarios cabría destacar los siguientes: especulaciones sobre la ascendencia e identidad de los personajes, astrólogos, adivinos o videntes que pronostican la vida de monarcas y nobles; digresiones históricas y rupturas de la peripecia argumental para provocar el misterio sobre el desenlace de un hecho o suceso; intercalación de cuadros de costumbres abstractos, descriptivos, a fin de recrear el contexto urbano, de la época; presencia de embozados, de personajes disfrazados; intrigas familiares, rivalidades políticas, división del mundo novelesco; saltos en los capítulos para incrementar la intriga y revelar al mismo tiempo determinados aspectos desconocidos por el lector; personajes antónimos de la virtud, aviesos, endiablados; elementos propios de las novelas góticas, como pasadizos, puertas secretas, ejecuciones sangrientas, sádicas, inhumanas; utilización de objetos o prendas como señas de identidad a fin de identificar la ascendencia de una persona o como salvoconducto de un personaje en cuestión para llevar a cabo un determinado cometido; utilización de pócimas milagrosas para curar heridas mortales o de difícil curación; administración de bebedizos o brebajes para producir la muerte; duelos y desafíos por cuestiones de honor; muertes aparentes, entre otros recursos. Presencia también de determinados temas cruciales en las novelas históricas, como las relaciones y despechos amorosos, idealización de la dama, encarcelamientos provocados por desavenencias conyugales, triángulos amorosos. Asuntos o motivos que se entrecruzan entre las relaciones existentes entre Blanca de Borbón y María de Padilla con el resto de personajes trascendentales en El primogénito de Alburquerque.
} 
seguidas por López Soler hasta el final del relato, hasta la muerte de su hermanastro, el monarca Pedro i el Cruel. Un final que concluye con su coronación como rey de Castilla y el retiro de Martín Gil de Alburquerque a su señorío en busca de armonía y sosiego, alejándose por completo de la corte y buscando una paz espiritual en una época marcada por una guerra fratricida que le estigmatizaría desde el principio al final de sus días.

El primogénito de Alburquerque fue la primera novela histórica publicada en España cuya peripecia argumental se infarta en la época de Pedro i el Cruel y en las rivalidades nobiliarias del momento. Bien es verdad que en el año 1831 se publica una novela en Francia -Don Martín Gil. Histoire du temps de Pierre-le-Cruel-de Mortonval ${ }^{39}$ que inicia el interés por dicho reinado y sus guerras civiles. Novela que no tuvo ninguna repercusión en Francia ni en España, pues la célebre novela de Alexandre Dumas, Pierre-le-Cruel (1841) se basa en la obra de Trueba The Romance of History. Spain (1830), traducida al francés con el título L'Espagne romantique (1832) y en su novela escrita en inglés The Castilian, publicada en el año 1829, y cuyo asunto, el enfrentamiento entre Pedro I y Enrique de Trastámara, escenificaba un episodio histórico atractivo para los extranjeros y también para los propios liberales exiliados. En cualquier caso la primacía del asunto en España le corresponde a López Soler, iniciando un motivo temático que tendrá su continuación en la narrativa del siglo XIX, como en el caso de M. Torrijos -El puñal de Tratámara (1858) y Justicias del rey don Pedro (1858)-, A. Bolangero -Pedro I de Castilla o El grito de la venganza (1852)-, F. Fernández y González -Men Rodríguez de Sanabria (Memorias del tiempo del rey don Pedro el Cruel (1853), La cabeza del rey don Pedro (1856), La piel de justicia, memorias del tiempo de D. Pedro I el Cruel (1874), Doña María Coronel (episodio del reinado de don Pedro el Cruel (1874), El rico-hombre de Alcalá (Episodio del reinado de don Pedro I el Cruel (1875)-, E. Hernández y Fernández -Don Pedro el Cruel (1872)-, R. Ortega y Frías -Un reinado de sangre (1879)—, entre otros autores. Conflictos, reyertas y enemistades que también fueron trasladados a la ópera, como en el caso de Donizetti -María de Padilla-, Eslava - Pietri il Crudele- o de Reparaz Don Pedro el Cruel. Mosaico de obras y de autores que dieron a conocer al público de la época la compleja y complicada historia que puso punto final a la vida de Pedro I el Cruel y dio inicio como reyes de Castilla a la dinastía de los Trastámara.

\section{BibliografíA}

Álvarez Rubio, M. R., «Pedro el Cruel», en Leonardo Romero Tobar, Temas literarios hispánicos, Zaragoza, Prensas de la Universidad, 2013, pp. 197-216.

\footnotetext{
${ }^{39}$ Mortonval [Alexandre Furcy Guesdon], Don Martín Gil. Histoire du temps de Pierre-le-Cruel, Paris, Eugène Renduel, 1831.
} 
Caldera, E., Primi manifesti del romanticismo spagnolo, Pisa, Istituto di Letteratura Spagnola e Hispano-Americana dell'Università di Pisa, 1962.

Crónica de los Reyes de Castilla, desde don Alfonso el Sabio, hasta los católicos don Fernando y doña Isabel, con las enmiendas del Secretario Gerónimo Zurita y las correcciones y notas de Eugenio de Llaguno, Madrid, Imprenta de S. Agustín Sancha, 1779-1780.

DurÁn, A., Discurso sobre el influjo que ha tenido la crítica moderna en la decadencia del Teatro Antiguo Español, y sobre el modo con que debe ser considerado para juzgar convenientemente de su mérito peculiar, Madrid, Imprenta de Ortega y Compañía, 1828.

- Discurso sobre el influjo que ha tenido la crítica moderna en la decadencia del Teatro Antiguo Español, y sobre el modo con que debe ser considerado para juzgar convenientemente de su mérito peculiar. Introduction and notes by D. L. Shaw, University of Exeter, 1973.

- Colección de romances castellanos anteriores al siglo XVIII, Madrid, Amarita y Aguado, 1828-1832, 5 vols.

Fernández SuÁrez, L. y J. Reglá CAPitol, «España cristiana. Crisis de la Reconquista. Luchas civiles», en Historia de España de Menéndez Pidal, Madrid, Espasa Calpe, 1991, pp. 3-42- y 99-158.

GIES, D. T., Agustín Durán. A Biography and Literary Appreciation, London, Tamesis Books, 1975.

LARRA, M. J. de, «Discurso sobre el influjo que ha tenido la crítica moderna en la decadencia del teatro antiguo español, y sobre el modo con que debe ser considerado para juzgar convenientemente su mérito peculiar, por D.A.D.», Revista Española, (2 de abril 1833), p. 464.

López de Ayala, P., Crónicas de los reyes de Castilla D. Pedro, D. Enrique II, D. Juan I, D. Enrique III, Madrid, Sancha, 1779-1880, 2 vols.

Ledo del Pozo, J., Apología del rey Don Pedro de Castilla, conforme a la crónica verdadera de D. Pedro López de Ayala, Madrid, Imprenta de Hernández, s. a. [1780].

- Historia de la nobilísima villa de Benavente con la antigüedad de su Ducado, principio de su Condado, sucesión y hazañas heroicas de sus condes, Zamora, por Vicente Vallecillo, 1853.

LÓPEz SOLER, R., «Análisis de la cuestión agitada entre románticos y clasicistas», El Europeo, I, 7 (1823), p. 208.

, «Conclusión del análisis de la cuestión agitada entre románticos y clasicistas (continuación)», El Europeo, I, 8 (1823), p. 258.

, Los bandos de Castilla o El Caballero del Cisne. Novela original española, Valencia, Imprenta de Cabrerizo, 1830.

El primogénito de Alburquerque, por don Gregorio Pérez de Miranda, Madrid, Imprenta de Repullés, 1833-1834. 
Marrast, R., José Espronceda y su tiempo. Literatura, sociedad y política en tiempos del Romanticismo, Barcelona, Editorial Crítica, 1989.

Meregalli, P., Pietro di Castiglia nella letteratura, Milan/Venecia, La Goliardica, s.a.; G. Moya, Don Pedro el Cruel: Biología, política y tradición literaria en la figura de Pedro I de Castilla, Madrid, Júcar, 1975.

Morote, P., Antigüedad y blasones de la ciudad de Lorca e Historia de Santa María de las Huertas que el Rey Don Alfonso el Sabio trajo para su Conquista, y defensa, año de 1242, Murcia, Francisco Joseph López Mesnier, 1741.

Mortonval [Alexandre Furcy Guesdon], Don Martín Gil. Histoire du temps de Pierre-leCruel, Paris, Eugène Renduel, 1831.

Poetas castellanos anteriores al siglo XV. Colección hecha por Don Tomás Antonio Sánchez, continuada por el Excelentísimo Señor Don Pedro José Pidal, considerablemente aumentada e ilustrada, a vista de los códices y manuscritos antiguos, por Don Florencio Jover, Madrid, BAE, 1864.

Romero Larrañaga, G., Cuentos históricos, leyendas antiguas y tradiciones populares de España, Madrid, I. Boix, 1841.

Rosell, C., Crónicas de los reyes de Castilla desde Don Alfonso el Sabio, hasta los católicos Don Fernando y Doña Isabel. Colección ordenada por..., Madrid, M. Rivadeneyra, 1875.

Sabater, P., D. Enrique el Bastardo, conde de Trastámara. Drama histórico en seis actos, Valencia, Imprenta de López y Compañía, 1841.

Salazar y Acha, J., La casa del Rey de Castilla y León en la Edad Media, Madrid, Centro de Estudios Políticos y Constitucionales, 2000.

SAN MARTíN, R., «Un viaje por el mito del rey Cruel: la literatura y la historia después del Romanticismo», Revista de Literatura, 129 (2003), pp. 59-84.

SINuÉs, M. P., «El ángel de la muerte. Leyenda histórica del siglo XIV», en Mis vigilias, Zaragoza, Imprenta, Cristóbal Juste y Olona, 1854.

Valdaliso Casanova, C., Historiografía y legitimación dinástica. Análisis de la Crónica de Pedro I el Cruel, Valladolid, Universidad de Valladolid, 2010.

Valdeón Baruque, J., Pedro i el Cruel y Enrique de Trastámara. ¿La primera guerra civil española?, Madrid, Aguilar-Santillana, 2003.

Vera y Figueroa, J. A., El Rey D. Pedro defendido, ofrecido a la Majestad del Rey Don Felipe $I V$, nuestro señor, por..., conde de la Roca, Vizconde de Sierra-brava, Señor de las Villas de Torre-mayor, Enguidanos y la Pesquera, Comendador de LaBarca en la Orden de Santiago, Madrid, Francisco García, impresor del Reino, 1647. 